\title{
Sex-specific biochemical and histological differences in gonads of sea urchins (Psammechinus miliaris) and their response to phenanthrene exposure
}

\author{
Sabine Schäfer*,1, Doris Abele, Ellen Weihe, Angela Köhler \\ Alfred Wegener Institute for Polar and Marine Research within the Helmholtz Association, Am Handelshafen 12, 27570 Bremerhaven, Germany
}

\section{A R T I C L E I N F O}

\section{Article history:}

Received 16 August 2010

Received in revised form

14 October 2010

Accepted 19 October 2010

\section{Keywords:}

Sea urchin

Gonad

Lipofuscin

Energy charge

Phenanthrene

Ascorbate

Sex-specific differences

ATP

ATP/AMP ratio

Gametogenesis

\begin{abstract}
A B S T R A C T
Female and male individuals of the same species often differ with respect to their susceptibility to toxicant stress. In the present study, sea urchins (Psammechinus miliaris) of both sexes were exposed to high $\left(150 \mu \mathrm{g} \mathrm{L}^{-1}\right)$ and environmentally relevant $\left(5 \mu \mathrm{g} \mathrm{L}^{-1}\right)$ concentrations of phenanthrene over 10 days. While food intake was significantly decreased following exposure to $150 \mu \mathrm{g} \mathrm{L}^{-1}$ phenanthrene, histological indices (lipofuscin accumulation, fibrosis, oocyte atresia), energetic status (energy charge, sum adenylates, AMP/ATP ratio) as well as ascorbate levels in the gonads showed either little or no effect upon phenanthrene exposure. However, most parameters (vitamin C, energy charge, sum adenylates, AMP/ATP ratio, ATP and ADP concentrations, lipofuscin content, fibrosis) significantly differed between male and female animals. This study illustrates the difficulties to identify toxic injury in reproductive tissue as it may be superimposed by gametogenesis and spawning of gametes.
\end{abstract}

다 2010 Elsevier Ltd. All rights reserved.

\section{Introduction}

It is now well appreciated that female and male fish of the same species can differ with respect to their susceptibility to environmental contaminants (Afonso et al., 2003; Vega-Lopez et al., 2007). Examples are seen in female flounder (Platichthys flesus L.), where higher incidence of liver cancer is associated with sex-specific differences in NADPH metabolism important for xenobiotic biotransformation (Köhler and Van Noorden, 2003). Interestingly, in invertebrates male gametes often appear more susceptible to chemical stress than eggs (Au et al., 2001; Caldwell et al., 2004; Fitzpatrick et al., 2008). In the sea urchin, Anthocidaris crassipina, a higher sensitivity of males, assessed by reduced sperm motility and fertilization success of offspring was found after chronic $\mathrm{Cd}^{2+}$ exposure ( $\mathrm{Au}$ et al., 2001). In different invertebrate species, Caldwell et al. (2004) observed a reduced fertilization success after preincubation of sperm with the diatom-derived aldehyde $2 \mathrm{E}, 4 \mathrm{E}$ -

\footnotetext{
* Corresponding author. Tel.: +49 2611306 5375; fax: +49 26113065363.

E-mail addresses: Sabine.Schaefer@bafg.de (S. Schäfer), Doris.Abele@awi.de (D. Abele), e.weihe@gmx.de (E. Weihe), Angela.Koehler@awi.de (A. Köhler).

1 Present address: Federal Institute of Hydrology, Am Mainzer Tor 1, 56068 Koblenz, Germany.
}

decadienal, whereas the effect was negligible after preincubation of eggs. Another example is the blue mussel Mytilus trossulus with significantly reduced fertilization rates after exposure of sperm to $100 \mu \mathrm{g} \mathrm{L}^{-1}$ copper but not after exposure of eggs (Fitzpatrick et al., 2008).

To explore the differential toxicity of female and male germ cells reproductive tissue of adults can be used. Histopathological biomarkers in gonads can help to understand the mode of action of chemicals on processes related to reproduction (Au et al., 2001; Dietrich et al., 2009). In a recent study, severe histopathological alterations were observed in gonads of female Psammechinus miliaris following exposure to phenanthrene (Schäfer and Köhler, 2009), a low molecular weight, 3-ring polycyclic aromatic hydrocarbon (PAH), and a major component of total PAH compounds in marine waters (Law et al., 1997). PAHs are lipophilic organic compounds and widespread in the marine environment. They are considered hazardous substances by several European and regional directives aiming at protecting aquatic environments from anthropogenic impact (HELCOM, 2009; OSPAR, 2007; European Commission, 2008). Following exposure to $500 \mu \mathrm{g}$ phenanthrene $\mathrm{L}^{-1}$ for 20 days, disorganisation of the gonadal structure, fibrosis, aggregates of degenerating oocytes, as well as high numbers of atretic oocytes were found in female sea urchins (Schäfer and Köhler, 2009). However, background concentrations of

0141-1136/\$ - see front matter (c) 2010 Elsevier Ltd. All rights reserved.

doi:10.1016/j.marenvres.2010.10.004 
PAHs in seawater amount to only maximally $10.7 \mu \mathrm{g} \mathrm{L}^{-1}$ total PAHs (Law et al., 1997) and thus range at least 50-times lower than the test concentration in our previous study. Moreover, several countries set phenanthrene 'safe' levels for aquatic organisms equal or less than $4.6 \mu \mathrm{g} \mathrm{L}^{-1}$ (Law et al., 1997).

Histochemical and histological changes in gonadal tissues, which may be indicative for reproductive impairment, include increased lipofuscin accumulation, fibrosis, as well as oocyte atresia. Lipofuscin, also known as fluorescent age pigment, is an end product of protein and lipid peroxidation which accumulates as an ultimate consequence of oxidative stress (Au et al., 1999; Au, 2004; Terman and Brunk, 2004). In mussels and fish, contamination with PAHs has been associated with a more pronounced accumulation of lipofuscin in polluted groups compared to control groups (Krishnakumar et al., 1994, 1997; Au et al., 1999; Au, 2004). Nevertheless, even $500 \mu \mathrm{g} \mathrm{L}^{-1}$ phenanthrene did not accelerate lipofuscin deposition in ovaries of the sea urchin $P$. miliaris (Schäfer and Köhler, 2009). The second histopathological parameter, fibrosis, is often described to occur in reproductive tissues of fish after exposure to environmental contaminants (Dietrich et al., 2009). Fibrosis involves augmentation of collagen and more massive appearance of the connective tissue (Dietrich et al., 2009), and phenanthrene exposure increases fibrosis in sea urchin gonads (Schäfer and Köhler, 2009). Another histopathological parameter, easy to record in females, is the percentage of atretic oocytes in the ovaries. Atresia is a degenerative and resorptive process of oocytes which may become pathologic after chemical exposure (Blazer, 2002; Dietrich et al., 2009; Schäfer and Köhler, 2009).

Before histopathological manifestations occur in a tissue, biochemical modulations generally precede. One of the key responses of tissues or cells to toxicant exposure is a decrease of available energy and reducing power due to energy dependent protective mechanisms against xenobiotics and chemical detoxification. A measure for the energetic state of an organism, a tissue or a cell is the adenylate energy charge (EC) which is calculated as $\mathrm{EC}=(\mathrm{ATP}+\mathrm{ADP} / 2) /(\mathrm{ATP}+\mathrm{ADP}+\mathrm{AMP})$. Theoretically, $\mathrm{EC}$ varies from 0 to 1 , but in natural systems maximal values of $0.8-0.95$ are recorded. The energy charge is stabilized by adjusting the rate of ATP synthesis and consumption (Ataullakhanov and Vitvitsky, 2002). Adverse environmental conditions such as the presence of toxic substances are generally accompanied by a decreasing EC. Therefore, Ivanovici (1980) proposed the use of EC as an index for environmental stress. Since the 1980s, EC values have been measured in laboratory and field studies of polluted populations, to assess sublethal effects of chemical compounds on aquatic organisms (Verschraegen et al., 1985; Marazza et al., 1996; Schill and Köhler, 2004).

Critical components of defence systems against chemical stress in organisms are antioxidants (Goldstone et al., 2006) such as the non-enzymatic ascorbate, scavenger of highly reactive superoxide anions and other free radicals. Ascorbate, like the energy charge mostly measured biochemically, is involved in xenobiotic detoxification and inhibits mutagenesis and carcinogenesis (Beyer, 1994).

The present study aims at investigating the effects of an environmentally relevant concentration $\left(5 \mu \mathrm{g} \mathrm{L}^{-1}\right)$ as well as a high dose $\left(150 \mu \mathrm{g} \mathrm{L}^{-1}\right)$ of phenanthrene on gonads of sea urchins. Sea urchins and especially their gametes are widely used for assessing toxic effects of contaminants (Manzo, 2004). P. miliaris is a relatively small echinoid, found in the Atlantic from Scandinavia to the Azores, including the North Sea and the Baltic (Boschma et al., 1932; Campbell, 1977). Histological investigations were carried out in conjunction with biochemical measurements, to clarify whether female and male sea urchins are differently affected by exposure to phenanthrene.

\section{Materials and methods}

\subsection{Animal collection, acclimation and experimental set up}

Adult $P$. miliaris were collected with a beam trawl in the List Tidal Basin in the northern Wadden Sea (Germany) at $55^{\circ} 02^{\prime} 40 \mathrm{~N}$ and $08^{\circ} 27^{\prime} 25 \mathrm{E}$ in December 2006. They were sorted by sex according to the appearance of their gonadopores following Uhlig (1979) and transported to the laboratory in Bremerhaven. Sea urchins were kept in aquaria in a small recirculation system at a water temperature of $6{ }^{\circ} \mathrm{C}$ and fed with Fucus sp. Kelly (2001) has shown that changing photoperiod and temperature are important triggers for gametogenesis. Therefore, gametogenesis was artificially induced by simulating winter conditions of the natural habitat with gradually decreasing water temperatures as well as photoperiod to $3{ }^{\circ} \mathrm{C}$ and 8.8:15.2 h light:dark cycle, respectively, and increasing again to $6^{\circ} \mathrm{C}$ and 11.7:12.3 light:dark in March 2007. Prior to the start of the experiment, sea urchins were transferred to flasks containing $1.5 \mathrm{~L}$ seawater ( 4 test animals per flask) and acclimated for 3-4 days. Sea urchins were exposed in these flasks ( 4 animals in $1.5 \mathrm{~L}$ sea water) to either $5 \mu \mathrm{g} \mathrm{L}^{-1}$ phenanthrene, $150 \mu \mathrm{g} \mathrm{L}^{-1}$ phenanthrene (in each case phenanthrene was predissolved in acetone), to seawater plus $3 \mathrm{ppm}$ acetone as solvent control, or to sea water only $\left(8.6 \pm 0.6^{\circ} \mathrm{C}, 32.5 \pm 0.1\right.$ PSU, pH $8.1 \pm 0.1$, continuous aeration). Each treatment consisted of three replicate flasks per sex (12 animals $\times$ sex $\times$ treatment). Sea urchins were fed once at the beginning of the experiment with fresh macroalgae (Fucus serratus). Wet weight of $F$. serratus leftovers at the end of the experiment was recorded in each flask to calculate the net food intake as $\mathrm{mg}^{-1} \mathrm{day}^{-1}$. Water was renewed daily and phenanthrene or solvent only added at the respective concentrations.

\subsection{Sampling}

Samples were taken after ten days of exposure. Animals were weighed $( \pm 0.01 \mathrm{~g})$ and horizontal test diameters (HTD) $( \pm 1 \mathrm{~cm})$ were measured using callipers. The animals were dissected; the gonads were removed and weighed $( \pm 1 \mathrm{mg})$. The gonads were immediately either fixed for histopathology or frozen in liquid nitrogen for biochemical analyses. The gonad index (GI) was calculated as the wet weight of the gonad divided by the total somatic wet weight and expressed as percentage.

\subsection{Histology}

For histopathology, six samples per treatment and sex were taken and immediately fixed in Baker's Formol Calcium (4\% formaldehyde and $2 \%$ calcium acetate) over night. On the next day, the samples were transferred to gum sucrose (30\% sucrose and $1 \%$ gum arabicum) and stored at $4{ }^{\circ} \mathrm{C}$ until further processing. Histological samples were dehydrated with acetone and embedded in methacrylate as described in detail elsewhere (Köhler, 2004; Schäfer and Köhler, 2009). Serial sections of $2 \mu \mathrm{m}$ thickness were cut using a HM LEICA RM 2145 microtome and stained with the Alcian BluePAS technique for general tissue morphology or with the Schmorl's procedure for lipofuscin. The Alcian Blue-PAS technique was used instead of the conventional hematoxylin and eosin $(\mathrm{H} \& \mathrm{E})$ staining, since it was previously shown to function optimally for gonadal tissues (Schäfer and Köhler, 2009). Briefly, sections are stained with Alcian Blue according to Lendrum et al. (1972). Sections are placed overnight in aldehyde blocking solution ( $2 \%$ sodium chlorite in $6 \%$ acetic acid) and stained with PAS (periodic acid Schiff's reagent) as described by Schäfer and Köhler (2009). For the Schmorl's procedure, sections were stained with ferric chloride/potassium ferricyanide solution as described by Schäfer and Köhler (2009). This technique results in blue staining of lipofuscin granules. 
Histological sections were viewed with a microscope (Axioscope, Zeiss, Germany). Reproductive stage of each animal was determined according to the classification for sea urchins by Byrne (1990) and Kelly (2000). Lipofuscin was quantified as areal density [\%] in cross-sections of gonadal tissue with the aid of computerassisted image analysis at $100 \times$ magnification (Schäfer and Köhler, 2009). Fibrosis and untimely spawning were semi-quantitatively assessed. For determination of fibrosis, in each sample 5 randomly chosen areas were graded at $100 \times$ magnification according to a scaling scheme from 0 (no change) to 3 (severe alteration). Premature sea urchins may spontaneously shed part of their gametes (Spirlet et al., 1998) which can be recognized by vacated spaces in the acini previously occupied by maturing gametes. Untimely spawning was graded in each individual at $100 \times$ magnification according to a scaling scheme from 0 (no spawning) to 2 (severe spawning). Atretic oocytes and eggs identified by fading and vacuolisation of the cytoplasm, cell lysis and disruption of the nuclear membrane were counted at $600 \times$ magnification. Randomly selected oocytes and eggs of 100 were counted per sample and the data are expressed as percentage.

\subsection{Tissue metabolites}

Tissue adenylate (ATP, ADP, AMP) and ascorbate concentrations were simultaneously analysed by HPLC according to Lazzarino et al. (2003). At least eight gonad samples per treatment and sex were taken and ground in liquid nitrogen. Preparation of extracts and HPLC procedure have been documented previously by Weihe and Abele (2008). Ground gonad tissue (15-120 mg) was homogenised with a micropistill with ice-cold, nitrogen-saturated precipitation solution $\left(\mathrm{CH}_{3} \mathrm{CN}\right.$ [Acetonitril] $+10 \mathrm{mM} \mathrm{KH}_{2} \mathrm{PO}_{4}$, at a ratio of $3: 1, \mathrm{pH} 7.4$ ) at a $1: 10(\mathrm{w}: \mathrm{v})$ tissue to medium ratio. The precipitation solution was prepared weekly, and $\mathrm{pH}$ was checked daily. The homogenate was centrifuged at $20690 \times \mathrm{g}$ for $10 \mathrm{~min}$ at $4{ }^{\circ} \mathrm{C}$, and the clear supernatants were stored on ice. Pellets were supplemented with $1 \mathrm{ml}$ of the precipitation solution and resuspended for several seconds using an ultraturax, centrifuged again as above, and the supernatants combined. This extract was washed with the double volume of chloroform (10 s vortexed with HPLC grade $\mathrm{CH}_{3} \mathrm{Cl}$ ) and centrifuged as above. The upper aqueous phase, containing the water-soluble low molecular weight compounds, was collected and washed again twice with chloroform. Supernatants were then stored at $-80^{\circ} \mathrm{C}$ until measurement.

Samples were separated on a Beckman HPLC using a Kromasil $250 \times 4.6 \mathrm{~mm}, 5 \mu \mathrm{m}$ particle size column (Eka Chemicals, AB, Bohus, Sweden) and its own guard column. Injection volume was $50 \mu \mathrm{l}$ of extract. Some sea urchins had relatively small gonads and only small $(<50 \mathrm{mg}$ ) tissue samples could be processed, resulting in low extraction volumes which had to be diluted with $10 \mathrm{mM}$ $\mathrm{KH}_{2} \mathrm{PO}_{4}$, to obtain adequate volumes for handling. HPLC conditions (solvents, gradient, flow rate, detection) were applied as described in Lazzarino et al. (2003). AMP, ADP, ATP standards were purchased from Sigma. In the present study HPLC detection limits were $4.4 \mathrm{nM}$ ascorbate, $0.2 \mathrm{nM}$ AMP, $0.02 \mathrm{nM}$ ADP and $0.04 \mathrm{nM}$ ATP.

Metabolite concentrations were assessed using Karat Software 7.0. Energy charge (EC) was calculated after Atkinson (cf. Ataullakhanov and Vitvitsky, 2002) as EC $=($ ATP + ADP/2)/(ATP + ADP + AMP $)$.

The amount of total adenylates was calculated as total adenylates $=$ ATP + ADP + AMP.

\subsection{Statistics}

Since treatment and sex may affect behaviour (food intake), somatic parameters as well as biochemical composition of gonads (adenylates, ascorbate), data were analysed by means of a 2-way
ANOVA with interactive effect and a Fisher LSD as a post hoc test. If necessary, data were transformed prior to analysis to obtain normal distribution. Gonad index and gonad weight were ln- and log-transformed, respectively. Lipofuscin content and fibrosis were BoxCox-transformed with (lipofuscin $\left.{ }^{0.2}-1\right) / 0.4606$ and $\left((\text { fibrosis }+1)^{-0.6}-1\right) /-0.2748$. For oocyte atresia the effects of treatment and spawning were analysed using one-way ANOVA and Fisher LSD post hoc test. The significance level was set as $p<0.05$.

\section{Results}

\subsection{Food intake, growth and gonad index}

Food intake of $P$. miliaris was significantly reduced in sea urchins exposed to $150 \mu \mathrm{g}$ phenanthrene $\mathrm{L}^{-1}$ (Table 1 ). No sex difference was observed with respect to food intake of $P$. miliaris (2-way ANOVA, treatment $p=0.031$, sex $p=0.852$, interaction $p=0.313$, Tukey HSD, $p<0.05$ ).

Somatic size (HTD) and somatic weight did not differ between treatments or sexes (2-way ANOVA: HTD: $\operatorname{sex} p=0.580$, treatment $p=0.720$, sex $\times$ treatment $p=0.976$; somatic weight: $\operatorname{sex} p=0.757$, treatment $p=0.528$, sex $\times$ treatment $p=0.992$, Table 1 ). However, in all samples males had significantly less gonad weight compared to females (2-way ANOVA: $p=0.023$ ) with $577 \pm 417 \mathrm{mg}$ vs. $888 \pm 688 \mathrm{mg}$, respectively. Furthermore, males had significantly lower gonad indices than females (2-way ANOVA: $p=0.006$ ) with $4.2 \pm 2.6 \%$ and $6.3 \pm 3.4 \%$, respectively. Gonad weight was significantly reduced in phenanthrene-treated animals $\left(5 \mu \mathrm{g} \mathrm{L}^{-1}\right.$ and $150 \mu \mathrm{g} \mathrm{L}^{-1}$ ) compared to the (sea water only) control group $(p=0.046)$, but gonad index did not differ between all treatments $(p=0.066)$ (Table 2). No interaction of sex and treatment was found, either with respect to gonad weight or gonad index (gonad weight: $p=0.199, \mathrm{GI}: p=0.176$ ).

\subsection{Histology}

Except for one female, sea urchins were in the premature stage. Premature sea urchins are characterized by the presence of gametes in all stages of development. Mature gametes, eggs and spermatozoa, accumulate in the lumen of the gonadal acini, whereas the nutritive phagocytes are displaced to the acinal periphery (e.g., Byrne, 1990; Kelly, 2000). One female was partially spawned evident from large areas of vacant space between relict oocytes. This animal had been treated with $5 \mu \mathrm{g}$ phenanthrene $\mathrm{L}^{-1}$. As reproductive stage affects histocytological parameters such as lipofuscin content and fibrosis in sea urchin gonads (Schäfer and Köhler, unpublished), the partially spawned female was excluded from the following analyses.

\section{Table 1}

Food intake measured as mg $F$. serratus wet weight day ${ }^{-1}$. Mean net food intake of three replicate glass vessels were calculated $(n=3)$. Presented are mean values with standard deviations in parentheses. $\mathrm{f}=$ female, $\mathrm{m}=$ male. Different letters indicate significant differences between treatments (2-way ANOVA, treatment $p=0.031$, sex $p=0.852$, interaction $p=0.313$, Tukey HSD, $p<0.05)$.

\begin{tabular}{lll}
\hline Treatment & Sex & $\begin{array}{l}\text { Food intake } \\
{[\mathrm{mg} \mathrm{wet} \text { weight day }}\end{array}$ \\
\hline Control & $\mathrm{f}$ & $202(56)^{\mathrm{a}}$ \\
Control & $\mathrm{m}$ & $461(152)^{\mathrm{a}}$ \\
Solvent control & $\mathrm{f}$ & $182(104)^{\mathrm{a}}$ \\
Solvent control & $\mathrm{m}$ & $162(95)^{\mathrm{a}}$ \\
$5 \mu \mathrm{g} \mathrm{L}^{-1}$ phenanthrene & $\mathrm{f}$ & $188(100)^{\mathrm{a}}$ \\
$5 \mu \mathrm{g} \mathrm{L}^{-1}$ phenanthrene & $\mathrm{m}$ & $195(71)^{\mathrm{a}}$ \\
$150 \mu \mathrm{g} \mathrm{L}^{-1}$ phenanthrene & $\mathrm{f}$ & $113(87)^{\mathrm{b}}$ \\
$150 \mu \mathrm{g} \mathrm{L}^{-1}$ phenanthrene & $\mathrm{m}$ & $58(76)^{\mathrm{b}}$ \\
\hline
\end{tabular}


Table 2

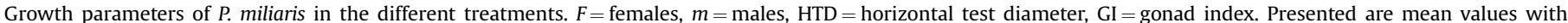

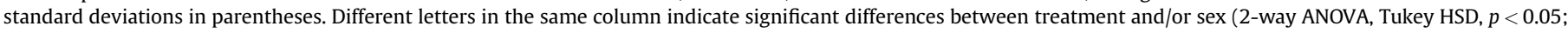

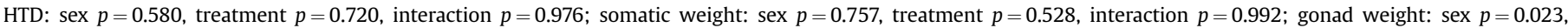
treatment $p=0.046$, interaction $p=0.199$, GI: $\operatorname{sex} p=0.006$, treatment $p=0.066$, interaction $p=0.176$ ).

\begin{tabular}{|c|c|c|c|c|c|c|}
\hline Treatment & Sex & $n$ & HTD [mm] & Somatic weight $[\mathrm{g}]$ & Gonad weight [mg] & GI [\%] \\
\hline Control & $\mathrm{f}$ & 11 & $30.5(2.8)$ & $13.5(3.7)$ & $1079(706)^{\mathrm{ac}}$ & $7.7(3.5)^{\mathrm{a}}$ \\
\hline Control & $\mathrm{m}$ & 12 & $31.3(2.9)$ & $14.0(3.1)$ & $712(348)^{\mathrm{bc}}$ & $5.3(2.9)^{b}$ \\
\hline Solvent control & $\mathrm{f}$ & 12 & $30.9(4.7)$ & $15.0(6.3)$ & $1096(806)^{\mathrm{acd}}$ & $6.8(3.1)^{\mathrm{a}}$ \\
\hline Solvent control & $\mathrm{m}$ & 12 & $31.2(4.0)$ & $14.8(5.2)$ & $448(164)^{\mathrm{bcd}}$ & $3.3(1.5)^{b}$ \\
\hline $5 \mu \mathrm{g} \mathrm{L}^{-1}$ phenanthrene & $\mathrm{f}$ & 10 & $29.4(4.4)$ & $12.6(4.9)$ & $622(606)^{\mathrm{ad}}$ & $5.1(3.7)^{\mathrm{a}}$ \\
\hline $5 \mu \mathrm{g} \mathrm{L}^{-1}$ phenanthrene & $\mathrm{m}$ & 12 & $30.3(3.7)$ & $13.1(3.9)$ & $731(633)^{\mathrm{bd}}$ & $5.0(3.3)^{b}$ \\
\hline $150 \mu \mathrm{g} \mathrm{L}^{-1}$ phenanthrene & $\mathrm{f}$ & 11 & $30.6(3.7)$ & $13.6(4.6)$ & $710(544)^{\mathrm{ad}}$ & $5.4(3.2)^{\mathrm{a}}$ \\
\hline $150 \mu \mathrm{g} \mathrm{L}^{-1}$ phenanthrene & $\mathrm{m}$ & 12 & $30.6(4.9)$ & $14.0(5.6)$ & $416(253)^{\mathrm{bd}}$ & $3.3(2.2)^{b}$ \\
\hline
\end{tabular}

In all groups, lipofuscin content measured as areal density in gonadal cross-sections was significantly increased in males compared to females with $1.716 \pm 1.447 \%$ and $0.417 \pm 0.705 \%$, respectively (Fig. 1a). Treatment had no effect on lipofuscin content (2-way ANOVA: treatment $p=0.371$, sex $p<0.001$, interaction $p=0.509$ ). Next to lipofuscin, fibrosis was significantly increased in males compared to females (Fig. 1b, Mann-Whitney rank sum test, $p=0.011$ ) whereas no treatment effect was found (Kruskal-Wallis one-way ANOVA on ranks: females: $p=0.059$; males: $p=0.255$ ). The effect of treatment on fibrosis had to be analysed by nonparametric tests since the data failed normal distribution despite box-cox transformation.

As spawning may be induced in invertebrates by exposure to chemicals (Cajaraville et al., 1992) spawning was semi-quantitatively recorded in sea urchin gonads. Phenanthrene exposure did not induce the untimely release of gametes (Kruskal-Wallis ANOVA on ranks, $p=0.068$ ). Furthermore, treatment with either phenanthrene or solvent alone had no effect on the percentage of atretic oocytes (one-way ANOVA, $p=0.257$ ). However, in all treatments (controls and phenanthrene exposed) spontaneous spawning events significantly increased the incidence of atretic oocytes (one-way ANOVA, $p<0.001$, Fisher LSD, $p<0.05$, Fig. 2). Animals that had released many gametes - visible by large areas of vacant space in the gonads - had the highest percentage of atretic oocytes. The lowest numbers of atretic oocytes were found in females that had not yet released gametes. No other tissue alterations, such as disorganisation of the acinal structure, aggregation of degenerating oocytes, inflammatory reactions or changes in nutritive phagocytes were observed in the gonads.

\subsection{Parameters of energy charge and ascorbate concentrations}

Adenylate concentrations differed very little between treatments, but were significantly different in female and male sea urchins (Fig. 3). Moreover, metabolite concentrations were highly variable in all samples (compare Fig. 3d, Table 3). Energy charge (EC) (Fig. 3a) was $0.25 \pm 0.19$ in females and significantly higher than in males which had an EC of only $0.15 \pm 0.18$. No differences were found in the EC between treatments (2-way ANOVA, sex $p<0.001$, treatment $p=0.188$, interaction $p=0.600)$. The sum of the adenylates (Fig. 3b) were 1.5 times higher in females $\left(528 \pm 311 \mathrm{nmol} \mathrm{g}^{-1}\right.$ fresh weight) than in males with only $342 \pm 287 \mathrm{nmol} \mathrm{g}^{-1}$ fresh weight.

Furthermore, treatment and the interaction of treatment and sex had significant effects on total adenylates (2-way ANOVA, sex $p=0.002$, treatment $p=0.004$, interaction $p=0.024)$. Within females, significantly higher adenylate values were found in the $150 \mu \mathrm{g} \mathrm{L}^{-1}$ phenanthrene-treated group compared to the solvent control and the $5 \mu \mathrm{g} \mathrm{L}^{-1}$ phenanthrene-treated group. Moreover, controls had significantly higher total adenylate values than the $5 \mu \mathrm{g} \mathrm{L}^{-1}$ phenanthrene-treated group, whereas solvent without phenanthrene had no effect. Male sea urchin had significantly lower gonad adenylate concentrations in both phenanthrenetreated groups compared to controls. In general, the differences in sum adenylates between treatments reflect changes of all adenylates (AMP, ATP, ADP) (compare Table 3 ) and not of a specific component. Interactive effects of treatment and sex on total adenylate concentrations as well as other parameters are also illustrated in Table 4.
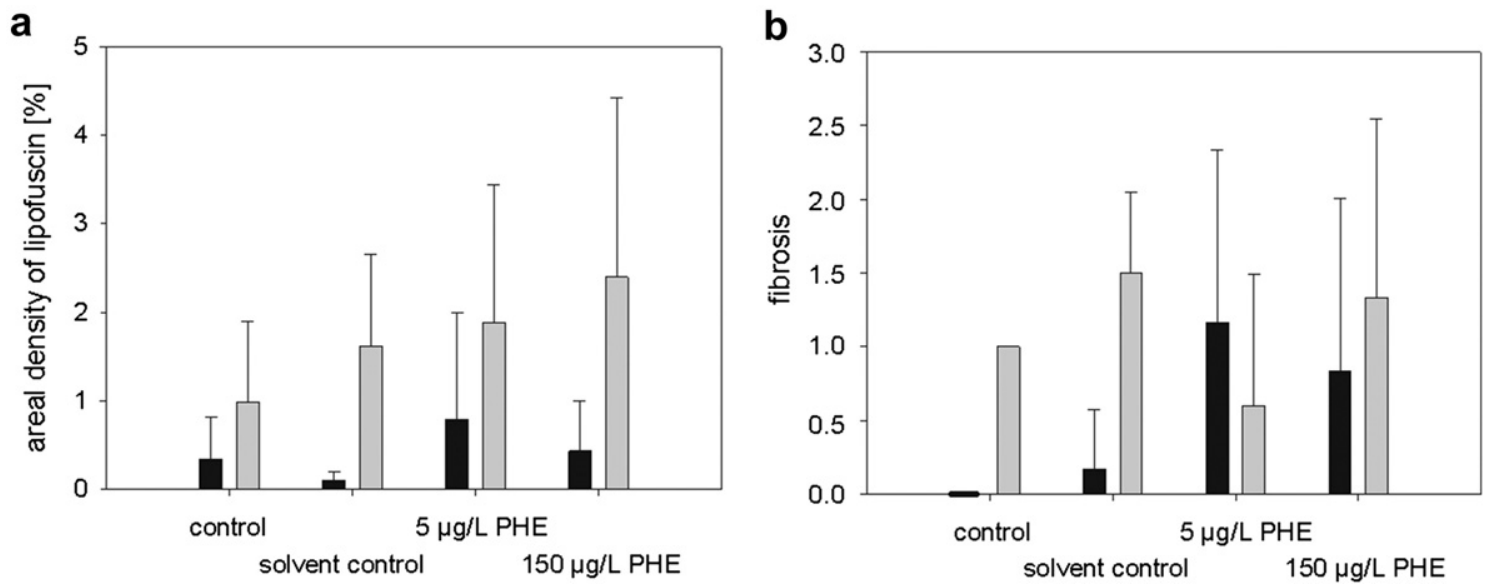

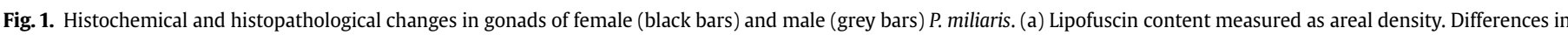

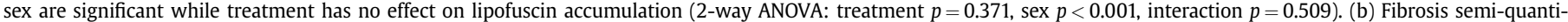

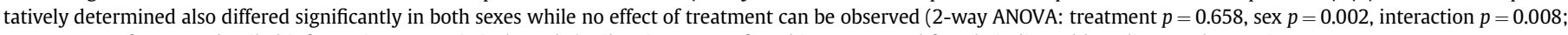
compare text for more detailed information on statistical results). Fibrosis was not found in any control female indicated by a line on the $x$-axis. 


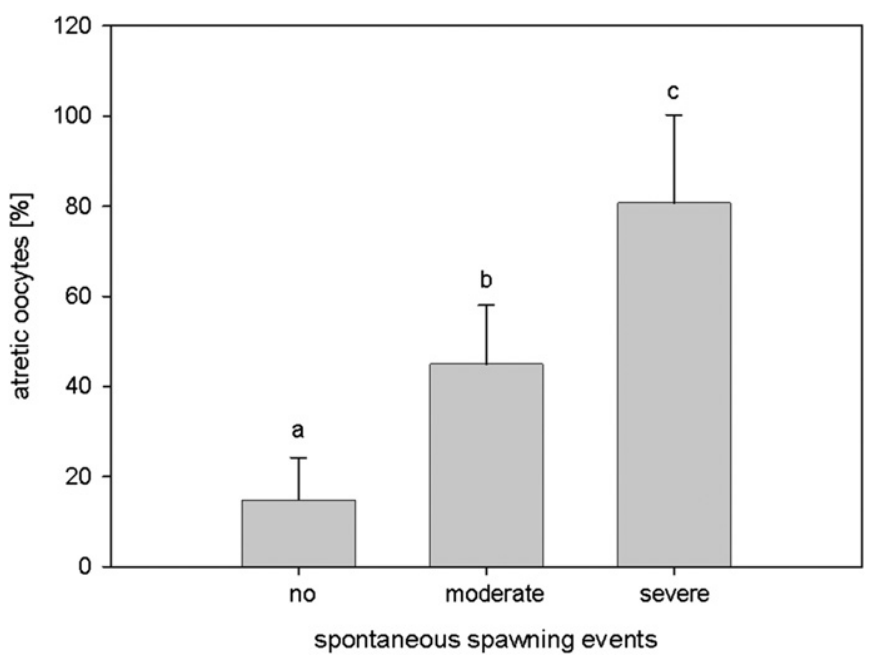

Fig. 2. Percentage of atretic oocytes in ovaries of $P$. milaris in dependence of spawning. Animals that had underwent severe spawning events visible as large areas of space vacated by shed oocytes and eggs had significantly increased numbers of atretic oocytes (one-way ANOVA, $p<0.001$, Fisher LSD, $p<0.05$ ).

The AMP/ATP ratio (Fig. 3c) was $80 \pm 125$ in males, around four times higher than in females. Treatment had no significant effect on the ratio of AMP/ATP (2-way ANOVA, sex $p<0.001$, treatment $p=0.416$, interaction $p=0.839$ ). The different AMP/ATP ratios in females and males result from significantly higher ATP levels in females, whereas AMP levels did not differ between sexes (Table 3).
However, treatment, as well as the interaction between sex and treatment, had significant effects on AMP concentrations (2-way ANOVA, treatment $p=0.016$, sex $p=0.228$, interaction $p=0.031$, Table 4). Combining data of females and males, AMP levels were significantly lower following exposure to $5 \mu \mathrm{g} \mathrm{L}^{-1}$ phenanthrene compared to the three other groups. Within females, AMP concentrations differed only between the $5 \mu \mathrm{g} \mathrm{L}^{-1}$ vs. the $150 \mu \mathrm{g} \mathrm{L}^{-1}$ phenanthrene group. Moreover, AMP levels in females were significantly elevated in the $150 \mu \mathrm{g} \mathrm{L}^{-1}$ phenanthrene treatment compared to the solvent control. In contrast, AMP levels in males were significantly lower in the $150 \mu_{\mathrm{g} \mathrm{L}}^{-1}$ phenanthrene vs. the solvent control group. In the $150 \mu \mathrm{g} \mathrm{L}^{-1}$ group, AMP values were also significantly lower in males compared to females.

ATP concentrations differed significantly between treatments and sexes (2-way ANOVA, treatment $p=0.013$, sex $p<0.001$, interaction $p=0.214$ ). Levels of ATP were significantly higher in females than males and lower in the $5 \mu \mathrm{g} \mathrm{L}^{-1}$ phenanthrene group than the three other groups. Similarly, concentrations of ADP were higher in females than in males and lower following exposure to $5 \mu \mathrm{g} \mathrm{L}^{-1}$ phenanthrene compared to the other treatments. Sex and treatment had an interactive effect on ADP levels (2-way ANOVA, treatment $p=0.005$, sex $p<0.001$, interaction $p=0.048$, Table 4). ADP concentrations were significantly lower in males than in females in the control and in the $150 \mu \mathrm{g} \mathrm{L}^{-1}$ group. Within females, the $5 \mu \mathrm{g} \mathrm{L}^{-1}$ group had significantly lower ADP values than the $150 \mu \mathrm{g} \mathrm{L}^{-1}$ exposure group and the seawater control. Likewise, exposure to $5 \mu \mathrm{g} \mathrm{L}^{-1}$ phenanthrene resulted in significantly lower ADP values than the $150 \mu \mathrm{g} \mathrm{L}^{-1}$ and the solvent control within males. a

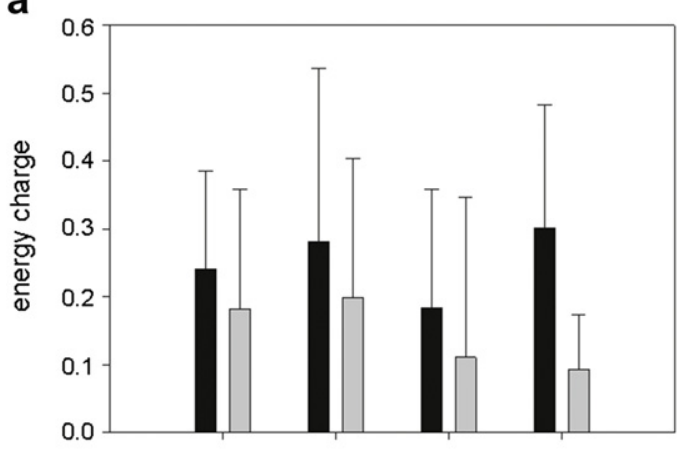

C

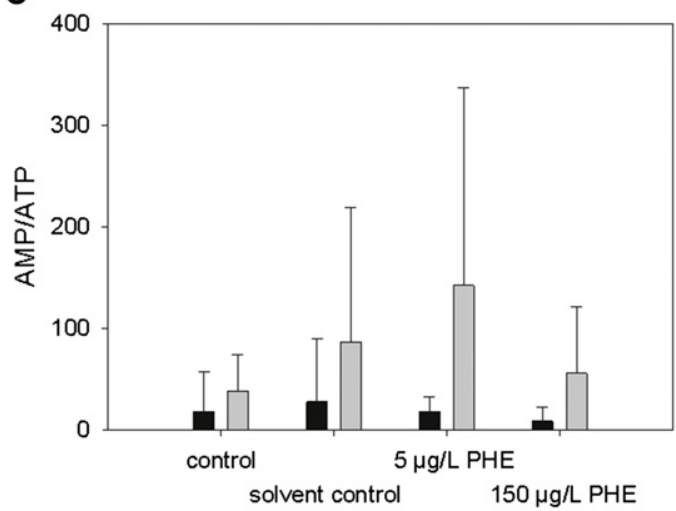

b

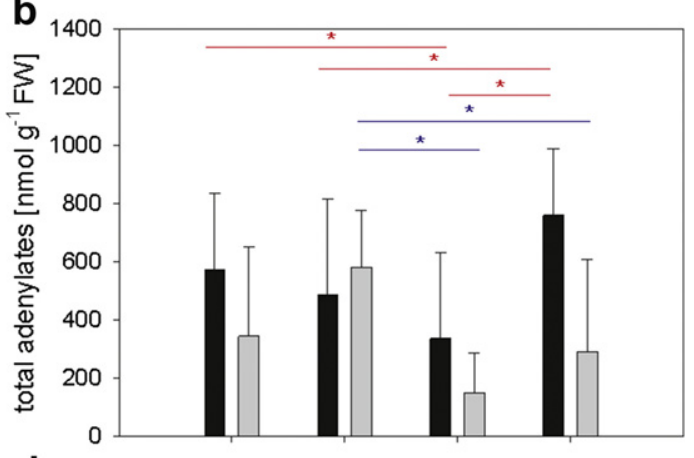

d

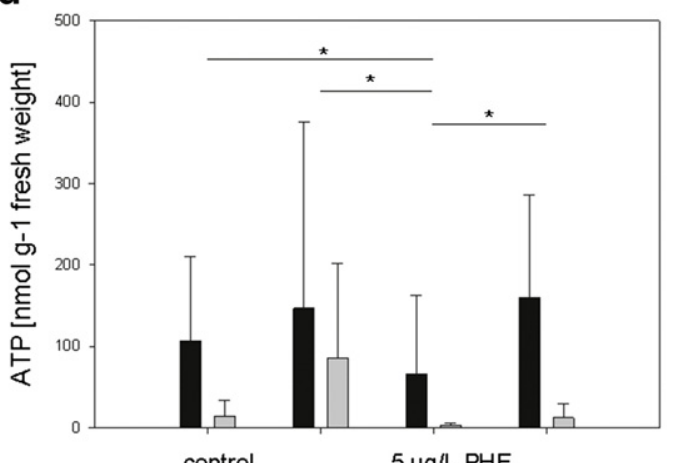

solvent control $\quad 150 \mu \mathrm{g} / \mathrm{L} \mathrm{PHE}$

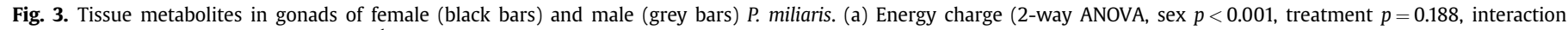

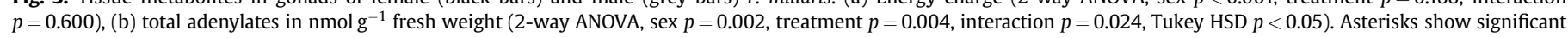

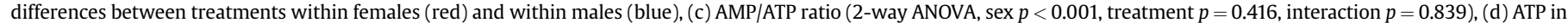

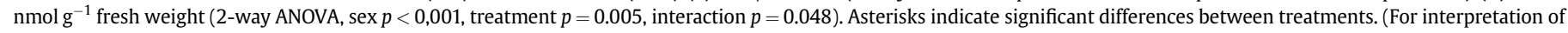
the references to colour in this figure legend, the reader is referred to the web version of this article.) 
Table 3

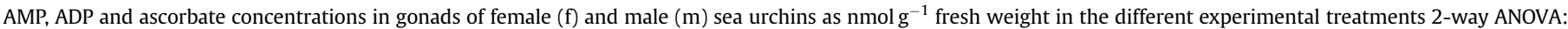

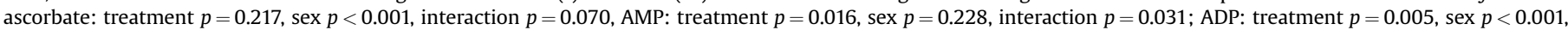
interaction $p=0.048$. Since treatment and sex had interactive effects on the levels of AMP and ADP results from the statistical analyses are presented in detail in Table 4.

\begin{tabular}{|c|c|c|c|c|c|}
\hline Treatment & Sex & $n$ & $\mathrm{AMP}\left[\mathrm{nmol} \mathrm{g}^{-1} \mathrm{FW}\right]$ & $\mathrm{ADP}\left[\mathrm{nmol} \mathrm{g}^{-1} \mathrm{FW}\right]$ & Ascorbate $\left[\mathrm{nmol} \mathrm{g}^{-1} \mathrm{FW}\right]$ \\
\hline Control & $\mathrm{f}$ & 11 & $342(109)$ & $124(87)$ & $958(275)$ \\
\hline Control & $\mathrm{m}$ & 9 & $275(232)$ & $56(86)$ & $134(58)$ \\
\hline Solvent control & $\mathrm{f}$ & 11 & $242(166)$ & $100(87)$ & $828(353)$ \\
\hline Solvent control & $\mathrm{m}$ & 9 & $378(124)$ & $117(107)$ & $202(67)$ \\
\hline $5 \mu \mathrm{g} \mathrm{L}^{-1}$ phenanthrene & $\mathrm{f}$ & 10 & 203 (159) & $67(87)$ & $873(294)$ \\
\hline $5 \mu \mathrm{g} \mathrm{L}^{-1}$ phenanthrene & $\mathrm{m}$ & 9 & $140(127)$ & $6(10)$ & $219(104)$ \\
\hline $150 \mu \mathrm{g} \mathrm{L}^{-1}$ phenanthrene & $\mathrm{f}$ & 8 & $430(147)$ & $171(97)$ & $983(260)$ \\
\hline $150 \mu \mathrm{g} \mathrm{L}^{-1}$ phenanthrene & $\mathrm{m}$ & 9 & 237 (227) & $43(75)$ & $241(104)$ \\
\hline
\end{tabular}

Ascorbate levels in females were $906 \pm 296 \mathrm{nmol} \mathrm{g}^{-1}$ fresh weight and five times higher than in males where ascorbate ranged at $199 \pm 92 \mathrm{nmol} \mathrm{g}^{-1}$ fresh weight (Table 3 ). Whereas sexes differed significantly, no effect of treatment on ascorbate levels was detected (2-way ANOVA, treatment $p=0.217$, sex $p<0.001$, interaction $p=0.070)$.

\section{Discussion}

Generally, we observed either no or little effects of phenanthrene on the gonads of the sea urchin P. miliaris. Higher susceptibility of invertebrate sperm than eggs to toxicant stress, as reported in the literature, does obviously not exist in sea urchin testes vs. ovaries exposed to phenanthrene. However, the data indicate significant sex-specific differences in histological indices, as well as in gonad energetic status and ascorbate levels.

Pronounced accumulation of lipofuscin in fish liver and mussel digestive gland has been associated with oxidative stress caused by pollution with PAHs (Krishnakumar et al., 1994, 1997; Au et al., 1999; Au, 2004). In our study, lipofuscin did not accumulate in phenanthrene-exposed gonads, consistent with a previous study where exposure to even $500 \mu \mathrm{g} \mathrm{L}-1$ of phenanthrene for 20 days did not result in elevated amounts of lipofuscin in ovaries of $P$. miliaris (Schäfer and Köhler, 2009). Since also exposure to the heavy metal lead failed to induce lipofuscin accumulation in sea urchin ovaries (Schäfer and Köhler, unpublished), fluorescent age pigment accumulation does not appear to be an appropriate indicator for pollutant-induced stress in sea urchin gonads. Instead, formation of lipofuscin in reproductive tissue of sea urchins depends on gonadal stage: In P. miliaris sampled at monthly intervals in the northern Wadden Sea, highest levels of lipofuscin were found at the end of gametogenesis in partially spawned or spent animals (Schäfer, 2010). Gonad lipofuscin accumulation may, therefore, simply indicate in vivo aging of relict gametes left after asynchronous spawning. In keeping with our present study, the field samples further revealed significantly higher levels of lipofuscin in males than females (Schäfer, 2010). Fibrosis of the acinal wall is also found significantly more often in partially spawned and spent animals (Schäfer, 2010), and in the present study male P. miliaris exhibited more severe fibrosis than females.

PAHs and oil are known to increase the prevalence of oocyte atresia in sea urchins (Schäfer and Köhler, 2009) as well as in other invertebrates (e.g., Lowe and Pipe, 1986; Tay et al., 2003; OrtizZarragoitia and Cajaraville, 2006). In the present study, oocyte atresia was not induced by exposure to 5 or even $150 \mu \mathrm{g}$ phenanthrene $\mathrm{L}^{-1}$ for 10 days, and only exposure to as much as $500 \mu \mathrm{g} \mathrm{L}^{-1}$ phenanthrene for 20 days increased atresia of previtellogenic oocytes in a previous study (Schäfer and Köhler, 2009). Oocyte atresia is, however, induced by the untimely release of gametes in the premature females (Fig. 2). Possibly, either the concentrations we used here ( 5 and $150 \mu \mathrm{g} \mathrm{L}^{-1}$ ) are too low to cause oocyte atresia within 10 days of exposure or degenerative processes following spontaneous spawning events superimpose the pollutant-mediated response. Interestingly, in the above mentioned study, we could not observe signs of degeneration in vitellogenic oocytes and mature eggs, which implied the later developmental stages of oocytes to be better protected against pollutant stress (Schäfer and Köhler, 2009). In the present study, atresia was, however, observed in all stages of oocytes as well as in ova indicating that degeneration of vitellogenic oocytes and ova result from spawning-induced phagocytosis of relict gametes. Alternatively, different timing of the experiments in regard to the reproductive cycle of the sea urchins may be responsible for the inconsistent observations. In contrast to the previous study (Schäfer and Köhler, 2009), we also failed to observe either aggregation of degenerating oocytes, disorganisation of the acinal structure, or changes in nutritive phagocytes after exposure of sea urchins to 5 and $150 \mu \mathrm{g}$ phenanthrene $\mathrm{L}^{-1}$.

The low EC with values of $0.01-0.76$ as well as the high AMP/ ATP ratios largely exceeding 1 were surprising at first glance: typical EC values for optimal conditions are in the range $0.8-0.9$ while stress conditions yield values in the range of $0.5-0.7$ or lower (Ivanovici, 1980; Verschraegen et al., 1985). But invertebrates are known to tolerate lower $E C$ values $\left(E_{\min }: 0.3-0.4\right)$ than vertebrates ( $\mathrm{EC}_{\min }$ : 0.5-0.6) due to a less stringent regulation and a low efficiency of the enzyme AMP deaminase (Raffin et al., 1994 cited in Marazza et al., 1996). AMP deaminase regulates cellular energy charge by degrading AMP to IMP, resulting in an increase in EC (Ataullakhanov and Vitvitsky, 2002). In dried/immotile and subsequently seawater-diluted/mobilized sperm of the sea urchin Hemicentrotus pulcherrimus the EC fell from 0.79 ( $=80 \%$ of high energy adenylates in the dried sperm) to $<0.5$ at $30 \mathrm{~min}$ after dilution (Mita and Yasumasu, 1983). AMP doubled the ATP concentrations when diluted sperm was kept at $0{ }^{\circ} \mathrm{C}$. Usually, ATP values exceed AMP concentrations (Ataullakhanov and Vitvitsky, 2002) but gametes, especially sperm, seem to represent an exception with a capacity for rapid recycling of resulting ADP by adenylate kinase to ATP + AMP (Mita and Yasumasu, 1983).

Our study revealed extremely low EC values and high AMP/ATP ratio suggestive of predominant anaerobic/glycolytic metabolism and minimal oxidative phosphorylation in the $P$. miliaris gonads. Bookbinder and Shick (1986) demonstrated that up to $92 \%$ of the heat dissipated by isolated ovaries of the sea urchin Strongylocentrotus droebachiensis derives from anaerobic metabolism. The ovaries have the capacity to produce large amounts of lactate and other glycolytic intermediates (Bookbinder and Shick, 1986), and the same applies to sperm (Mita and Yasumasu, 1983). Key glycolytic enzymes such as phosphofructokinase are activated by AMP and inhibited by ATP (Ataullakhanov and Vitvitsky, 2002) and the high AMP/ATP ratio in the gonads of $P$. miliaris in the present study probably upregulates glycolysis in the gametes while oxidative phosphorylation is simultaneously decreased (see also 
Boulekbache et al., 1989). Anaerobiosis in gonadal tissue may be advantageous for the protection of the developing gametes against reactive oxygen species which are formed during oxidative phosphorylation in the electron transport chain inside of the mitochondria (Turrens, 2003). Furthermore, predominant anaerobic glycolysis consumes glycogen in unfertilised eggs which saves phospholipid stores for oxidative metabolism after fertilization (Epel, 1978; Boulekbache et al., 1989). Relict eggs and sperm of partly spent gonads are presumably so energy deficient that fertilization and subsequent embryonic development are impossible, especially after exposure to $5 \mu \mathrm{g}$ phenanthrene $\mathrm{L}^{-1}$. However, our results seem to represent an extreme case. Luk'yanova (1994) measured EC values of around 0.9 in gonads of the sea urchin Strongylocentrotus intermedius, and we assume that these gonads were in a less progressed gametogenic state compared to our study. Future studies should further elucidate the effects of gamete maturity and season on gonad energy charge. Thus, the reproductive cycle is known to affect the EC of whole soft tissues due to the energy consumption for gametogenesis in the Pacific oyster (Crassostrea gigas) (Delaporte et al., 2006). In the blue mussel, Mytilus edulis, ATP concentrations and EC ratios in the soft body tissues could be related to the annual reproductive cycle and are supposed to reflect changing weight-proportions of hepatopancreas and gonads (Skjoldal and Barkati, 1982).

Adenylate measurements in our study further indicate sexspecific differences in energy metabolism of sea urchin gonads, with females having significantly higher gonad EC values, total adenylates as well as ATP levels. Interestingly, Allen (1996) hypothesized that the

Table 4

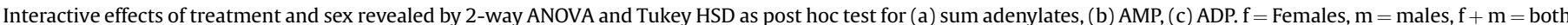

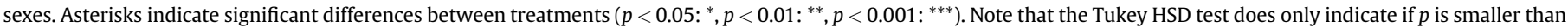

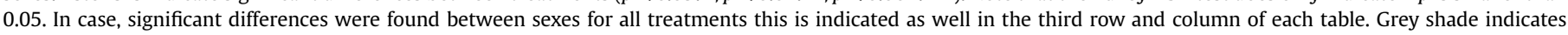
unnecessary cells.
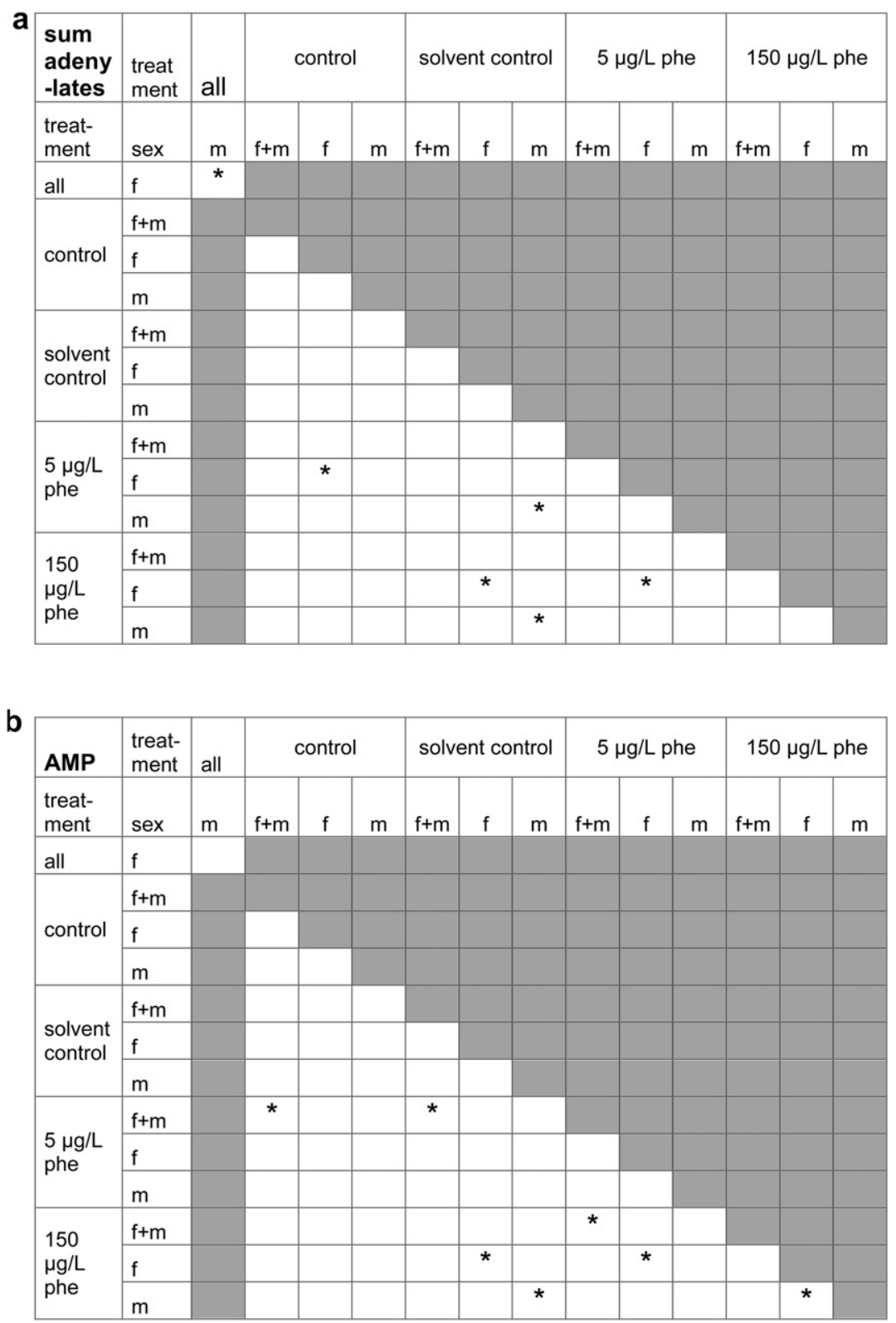


\begin{tabular}{|c|c|c|c|c|c|c|c|c|c|c|c|c|c|c|}
\hline \multirow{2}{*}{$\begin{array}{l}\text { ADP } \\
\text { treat- } \\
\text { ment }\end{array}$} & \multirow{2}{*}{$\begin{array}{l}\text { treat- } \\
\text { ment }\end{array}$} & \multirow{2}{*}{$\begin{array}{l}\text { all } \\
\mathrm{m}\end{array}$} & \multicolumn{3}{|c|}{ control } & \multicolumn{3}{|c|}{ solvent control } & \multicolumn{3}{|c|}{$5 \mu \mathrm{g} / \mathrm{L}$ phe } & \multicolumn{3}{|c|}{$150 \mu \mathrm{g} / \mathrm{L}$ phe } \\
\hline & & & $f+m$ & $f$ & $\mathrm{~m}$ & $f+m$ & $f$ & $\mathrm{~m}$ & $f+m$ & $f$ & $\mathrm{~m}$ & $f+m$ & $f$ & $\mathrm{~m}$ \\
\hline all & $f$ & $* * *$ & & & & & & & & & & & & \\
\hline \multirow{3}{*}{ control } & $f+m$ & & & & & & & & & & & & & \\
\hline & f & & & & & & & & & & & & & \\
\hline & $\mathrm{m}$ & & & * & & & & & & & & & & \\
\hline \multirow{3}{*}{$\begin{array}{l}\text { solvent } \\
\text { control }\end{array}$} & $f+m$ & & & & & & & & & & & & & \\
\hline & $f$ & & & & & & & & & & & & & \\
\hline & $\mathrm{m}$ & & & & & & & & & & & & & \\
\hline \multirow{3}{*}{$\begin{array}{l}5 \mu \mathrm{g} / \mathrm{L} \\
\text { phe }\end{array}$} & $f+m$ & & & & & & & & & & & & & \\
\hline & $f$ & & & & & & * & & & & & & & \\
\hline & $\mathrm{m}$ & & & & & & & * & & & & & & \\
\hline \multirow{3}{*}{$\begin{array}{l}150 \\
\mu \mathrm{g} / \mathrm{L} \\
\mathrm{phe}\end{array}$} & $f+m$ & & & & & & & & & & & & & \\
\hline & $f$ & & & & & & & & & * & & & & \\
\hline & $\mathrm{m}$ & & & & & & & & & & * & & * & \\
\hline
\end{tabular}

female germ line possesses undifferentiated mitochondria, incapable of ATP production for protection of oocytes against free radical damage of mitochondrial DNA. Further on, this would ensure transfer of intact mitochondrial DNA to the next generation. Sea urchin eggs possess 150,000 to 300,000 mitochondria of low respiratory activity (Dumollard et al., 2006), some of which may eventually differentiate fully only following fertilization of the egg and initiation of offspring. Contrary, mitochondria of short-lived sperm support maximal motility during fertilization (Allen, 1996). In sea urchin sperm, the single mitochondrion is located at the base of the sperm head, and mitochondrial respiration is activated to fuel motility. For sperm motility ATP generated by oxidative phosphorylation must be actively transported down the length of the tail where it is hydrolyzed by dynein ATPase for bending waves along the flagellum. Sea urchin spermatozoa utilize phosphocreatine to re-phosphorylate ADP (Tombes and Shapiro, 1985) and adenylate kinase (AK) further stabilizes ATP + AMP levels (Kinukawa et al., 2007).

A second hint towards a better antioxidant protection in female reproductive tissues are significantly higher levels of the antioxidant ascorbate compared to males. In general, testes of different animal phyla are known to contain high amounts of polyunsaturated fatty acids prone to oxidation (Halliwell and Gutteridge, 2007). In P. miliaris significantly increased levels of polyunsaturated fatty acids were found as well as a dramatic reduction in the fatty acids 22:6 $(n-3)$ and 22:5( $n-3)$ at increasing maturity (Hughes et al., 2006). Ovaries with higher ascorbate levels and less oxidizable compounds are presumably less susceptible to oxidative stress than testes. This is in keeping with less lipofuscin deposition in female sea urchin documented here and in our field study (Schäfer, 2010). Furthermore, we propose that lower ROS scavenging capacity might be responsible for the higher incidence of fibrosis in testes compared to ovaries, since fibrosis is suggested to be a scarring process in sea urchins (Schäfer, 2010).

After exposure to $5 \mu \mathrm{g} \mathrm{L}^{-1}$ phenanthrene for 10 days, we do not observe any behavioural changes (food intake), growth inhibition or histopathological alterations in the gonads of $P$. miliaris. Yet, biochemical analysis documented decreased levels of ATP in sea urchins treated with $5 \mu \mathrm{g} \mathrm{L}^{-1}$ phenanthrene compared to control treatments, whereas levels remained unchanged after treatment with $150 \mu \mathrm{g} \mathrm{L}^{-1}$. Increased energy consumption following exposure to the lower phenanthrene concentration may result from investments into cellular detoxification and protection. At the higher phenanthrene concentration $\left(150 \mu \mathrm{g} \mathrm{L}^{-1}\right)$ sea urchins may no longer be capable to counteract the toxic effects. Similar responses are proposed by Marazza et al. (1996) for the energy metabolism in shrimp stressed by exposure to ammonia. The reduced food intake of $P$. miliaris observed after exposure to $150 \mu \mathrm{g} \mathrm{L}^{-1}$ further shows severely affected behaviour, despite any clear histopathological or biochemical changes visible in gonads.

The complex responses of sea urchins to phenanthrene exposure highlight the necessity to measure various parameters at different levels of biological organization (tissue, individual) for detection of xenobiotically mediated adverse effects. Moreover, this investigation illustrates the difficulty for the identification of cause effect relationships of toxic injury in gonads, as they may be superimposed by the reproductive cycle and the release of gametes. Thus, some animals may have, e.g., less energy charge because they are intoxicated and some simply because the gonads are already partly spawned and residual gametes are aged or atretic. We suggest that the sex-specific differences of histopathological as well as biochemical parameters in the gonads of $P$. miliaris are related to the specific function of the gonadal tissue and reflect adaptative mechanisms of gametes to different life spans - the long-lived eggs and the short-lived sperm. Given the sperm's short life span and its relative "over-abundance", testes may not necessitate a high antioxidant scavenging potential and protective mechanisms against ROS formation and are able to "live" with low ascorbate levels, higher amounts of lipofuscin and higher incidence of fibrosis compared to ovaries. The physiological differences in mitochondrial functioning and antioxidant scavenging potential probably favour the higher susceptibility of sperm to chemical stress in comparison to more sustainable eggs in many invertebrates.

\section{Acknowledgements}

This study was financed by the Alfred Wegener Institute for Polar and Marine Research within the Helmholtz Association. It is part of a PhD study conducted at the Jacobs University Bremen. We 
thank Birgit Hussel and the crew of the FS Mya for collecting the sea urchins. We are grateful to Stefanie Meyer for technical support and to Tom Brey for statistical advice.

\section{References}

Afonso, L.O.B., Basu, N., Nakano, K., Devlin, R.H., Iwama, G.K., 2003. Sex-related differences in the organismal and cellular stress response in juvenile salmon exposed to treated bleached-kraft mill effluent. Fish. Physiol. Biochem. 29, $173-179$.

Allen, J.F., 1996. Separate sexes and the mitochondrial theory of ageing. J. Theor Biol. 180, 135-140.

Ataullakhanov, F., Vitvitsky, V., 2002. What determines the intracellular ATP concentration. Biosci. Rep. 22, 501-511.

Au, D.W.T., 2004. The application of histo-cytopathological biomarkers in marine pollution monitoring: a review. Mar. Pollut. Bull. 48, 817-834.

Au, D.W.T., Wu, R.S.S., Zhou, B.S., Lam, P.K.S., 1999. Relationship between ultrastructural changes and EROD activities in liver of fish exposed to benzo[a]pyrene. Environ. Pollut. 104, 235-247.

Au, D.W.T., Lee, C.Y., Chan, K.L., Wu, R.S.S., 2001. Reproductive impairment of sea urchins upon chronic exposure to cadmium. Part I: effects on gamete quality. Environ. Pollut. 111, 1-9.

Beyer, R.E., 1994. The role of ascorbate in antioxidant protection of biomembranes: interaction with vitamin E and coenzyme Q. J. Bioenerg. Biomembr. 26 (4), $349-358$.

Blazer, V.S., 2002. Histopathological assessment of gonadal tissue in wild fishes. Fish. Physiol. Biochem. 26, 85-101.

Bookbinder, L.H., Shick, J.M., 1986. Anaerobic and aerobic energy metabolism in ovaries of the sea urchin Strongylocentrotus droebachiensis. Mar. Biol. 93, 103-110.

Boulekbache, H., Bastin, J., Andriamihaja, M., Lefebvre, B., Joly, C., 1989. Ageing of fish oocytes: effects on adenylic nucleotides content, energy charge and viability of carp embryo. Comp. Biochem. Physiol. 93B, 471-476.

Boschma, H., de Beaufort, L.F., van Oort, E.D., Redeke, H.C., Roepke, W., 1932 Aflevering VI: Echinodermata. A.W. Sijthoff's Uitgeversmij N.V, Leiden.

Byrne, M., 1990. Annual reproductive cycles of the commercial sea urchin Paracentrotus lividus from an exposed intertidal and a sheltered subtidal habitat on the west coast of Ireland. Mar. Biol. 104, 275-289.

Cajaraville, M.P., Marigomez, J.A., Angulo, E., 1992. Comparative effects of the water accommodated fraction of three oils on mussels -1 . Survival, growth and gonad development. Comp. Biochem. Physiol. 102C, 103-112.

Caldwell, G.S., Bentley, M.G., Olive, P.J.W., 2004. First evidence of sperm motility inhibition by the diatom aldehyde 2E, 4E-decadienal. Mar. Ecol. Prog. Ser. 273 97-108.

Campbell, A.C., 1977. The Hamlyn Guide to the Seashore and Shallow Seas of Britain \& Europe. Hamlyn Publishing Group, London.

Delaporte, M., Soudant, P., Lambert, C., Moal, J., Pouvreau, S., Samain, J.F., 2006. Impact of food availability on energy storage and defense related hemocyte parameters of the Pacific oyster Crassostrea gigas during an experimental reproductive cycle. Aquaculture 254, 571-582.

Dietrich, D.R., Fournie, J., Gimeno, S., Krieger, H.O., Rumpf, S., Segner, H., Van der Ven, L., Wester, P., Wolf, J., 2009. Histological Analysis of Endocrine Disruptive Effects in Small Laboratory Fish. Wiley \& Sons Inc.

Dumollard, R., Duchen, M., Sardet, C., 2006. Calcium signals and mitochondria at fertilization. Semin. Cell. Develop. Biol. 17, 314-323.

Epel, D., 1978. Mechanisms of activation of sperm and egg during fertilization of sea urchin gametes. In: Moscona, A.A., Monroy, A. (Eds.), Current Topics in Developmental Biology, Fertilization. Academic Press, New York, San Francisco, London, pp. 185-245.

European Commission, 2008. Directive 2008/105/EC of the European Parliament and of the Council of 16 December 2008 on environmental quality standards in the field of water policy, amending and subsequently repealing Council Directives 82/176/EEC, 83/513/EEC, 84/156/EEC, 84/491/EEC, 86/280/EEC and amending Directive 2000/60/EC of the European Parliament and of the Council. Official Journal of the European Union.

Fitzpatrick, J.L., Nadella, S., Bucking, C., Balshine, S., Wood, C.M., 2008. The relative sensitivity of sperm, eggs and embryos to copper in the blue mussel (Mytilus trossulus). Comp. Biochem. Physiol. C. 147, 441-449.

Goldstone, J.V., Hamdoun, A., Cole, B.J., Howard-Ashby, M., Nebert, D.W., Scally, M., Dean, M., Epel, D., Hahn, M.E., Stegeman, J.J., 2006. The chemical defensome: environmental sensing and response genes in the Strongylocentrotus purpuratus genome. Dev. Biol. 300, 366-384

Halliwell, B.B., Gutteridge, J.M.C., 2007. Free Radicals in Biology and Medicine. Oxford University Press, Oxford.

HELCOM, 2009. Selected substances for immediate priority action. <http://www. helcom.fi/environment2/hazsubs/action/en_GB/list>, (access 25.07.09).

Hughes, A.D., Kelly, M.S., Barnes, D.K.A., Catarino, A.I., Black, K.D., 2006. The dual functions of sea urchin gonads are reflected in the temporal variations of their biochemistry. Mar. Biol. 148, 789-798.

Ivanovici, A.M., 1980. The adenylate energy charge in the estuarine mollusk, Pyrazus ebeninus - laboratory studies of responses to salinity and temperature. Comp. Biochem. Physiol. A. 66, 43-55.
Kelly, M.S., 2000. The reproductive cycle of the sea urchin Psammechinus miliaris (Echinodermata: Echinoidea) in a Scottish sea loch. J. Mar. Biol. Assoc. UK 80, 909-919.

Kelly, M.S., 2001. Environmental parameters controlling gametogenesis in the echinoid Psammechinus miliaris. J. Exp. Biol. Ecol. 266, 67-80.

Kinukawa, M., Nomura, M., Vacquier, V.D., 2007. A sea urchin sperm flagellar adenylate kinase with triplicated catalytic domains. J. Biol. Chem. 282, 2947-2955.

Köhler, A., 2004. The gender-specific risk to liver toxicity and cancer of flounder (Platichthys flesus (L.)) at the German Wadden Sea coast. Aquat. Toxicol. 70, 257-276.

Köhler, A., Van Noorden, C.J., 2003. Reduced nicotinamide adenine dinucleotide phosphate and the higher incidence of pollution-induced liver cancer in female flounder. Environ. Toxicol. Chem. 22, 2703-2710.

Krishnakumar, P.K., Casillas, E., Varanasi, U., 1994. Effect of environmental contaminants on the health of Mytilus edulis from Puget Sound, Washington, USA. 1. Cytochemical measures of lysosomal responses in the digestive cells using automatic image analysis. Mar. Ecol. Prog. Ser. 106, 249-261.

Krishnakumar, P.K., Casillas, E., Varanasi, U., 1997. Cytochemical responses in the digestive tissue of Mytilus edulis complex exposed to microencapsulated PAHs or PCBs. Comp. Biochem. Physiol. C. 118, 11-18.

Law, R.J., Dawes, V.J., Woodhead, R.J., Matthiessen, P., 1997. Polycyclic aromatic hydrocarbons (PAH) in seawater around England and Wales. Mar. Pollut. Bull. 34, 306-322.

Lazzarino, G., Amorini, A.M., Fazzina, G., Vagnozzi, R., Signoretti, S., Donzelli, S., Di Stasio, E., Giardina, B., Tavazzi, B., 2003. Single-sample preparation for simultaneous cellular redox and energy state determination. Anal. Biochem. 322, 51-59. Lendrum, A.C., Slidders, W., Fraser, D.S., 1972. Renal hyalin - study of amyloidosis and diabetic fibrinous vasculosis with new staining methods. J. Clin. Pathol. 25, 373.

Lowe, D.M., Pipe, R.K., 1986. Hydrocarbon exposure in mussels - a quantitative study of the responses in the reproductive and nutrient storage cell systems. Aquat. Toxicol. 8, 265-272.

Luk'yanova, O.N., 1994. Some biochemical parameters of marine invertebrates from a region of anthropogenic pollution. Russ. J. Ecol. 25, 435-439.

Manzo, S., 2004. Sea urchin embryotoxicity test: proposal for a simplified bioassay. Exotox. Environ. Safe. 57, 123-128.

Marazza, D., Bornens, P., LeGal, Y., 1996. Effect of ammonia on survival and adenylate energy charge in the shrimp Palaemonetes varians. Ecotoxicol. Environ. Safe. 34, 103-108.

Mita, M., Yasumasu, I., 1983. Metabolism of lipid and carbohydrate in sea urchin spermatozoa. Gamete Res. 7, 133-144.

Ortiz-Zarragoitia, M., Cajaraville, M., 2006. Biomarkers of exposure and reproduction-related effects in mussels exposed to endocrine disruptors. Arch. Environ. Contam. Toxicol. 50, 361-369.

OSPAR, 2007. OSPAR List of Chemicals for Priority Action. In: OSPAR Commission (ed). Convention for the protection of the marine environment of the NorthEast Atlantic, pp. 6.

Schäfer, S., Köhler, A., 2009. Gonadal lesions of female sea urchin (Psammechinus miliaris) after exposure to the polycyclic aromatic hydrocarbon phenanthrene. Mar. Environ. Res. 68, 128-136.

Schäfer, S., 2010. Reproductive Disorders in Sea Urchins (Psammechinus miliaris) Caused by Environmental Pollutants. Dissertation. Jacobs University, Bremen, January 2010. 154 pp.

Schäfer, S., Köhler, A., unpublished. The effect of lead on gonadal histochemistry and histology of sea urchin (Psammechinus miliaris).

Schill, R.O., Köhler, H.R., 2004. Does the environment or the source of the population define stress status and energy supply in the freshwater amphipod, Gammarus fossarum? Ecotoxicology 13, 683-695.

Skjoldal, H.R., Barkati, S., 1982. ATP content and adenylate energy charge of the mussel Mytilus edulis during the annual reproductive cycle in Lindåspollene, Western Norway. Mar. Biol. 70, 1-6.

Spirlet, C., Grosjean, P., Jangoux, M., 1998. Reproductive cycle of the echinoid Paracentrotus lividus: analysis by means of the maturity index. Int. J. Inv. Reprod. Dev. 34, 69-81.

Tay, K.L., Teh, S.J., Doe, K., Lee, K., Jackman, P., 2003. Histopathologic and histochemical biomarker responses of Baltic clam, Macoma balthica, to contaminated Sydney Harbour sediment, Nova Scotia, Canada. Environ. Health. Perspect. 111, 273-280.

Terman, A., Brunk, U.T., 2004. Aging as a catabolic malfunction. Int. J. Biochem. Cell. Biol. 36, 2365-2375

Tombes, R.M., Shapiro, B.M., 1985. Metabolite channeling: a phosphorylcreatine shuttle to mediate high energy phosphate transport between sperm mitochondrion and tail. Cell 41, 325-334.

Turrens, J.F., 2003. Mitochondrial formation of reactive oxygen species. J. Physiol. Lond 552, 335-344.

Uhlig G., 1979. Embryonalentwicklung beim Seeigel. Informationen und Text zu den Filmen für Forschung und Hochschulunterricht. Biologische Anstalt Helgoland und Institut für den wissenschaftlichen Film. Göttingen, pp. 17

Vega-Lopez, A., Martinez-Tabche, L., Martinez, M.G., 2007. Toxic effects of waterborne polychlorinated biphenyls and sex differences in an endangered goodeid fish (Girardinichthys viviparus). Environ. Int. 33, 540-545.

Verschraegen, K., Herman, P.M.J., Vangansbeke, D., Braeckman, A., 1985. Measurement of the adenylate energy charge in Nereis diversicolor and Nephtys $s p$ (Polychaeta, Annelida) - evaluation of the usefulness of AEC in pollution monitoring. Mar. Biol. 86, 233-240.

Weihe, E., Abele, D., 2008. Differences in the physiological response of inter- and subtidal Antarctic limpets Nacella concinna to aerial exposure. Aquat. Biol. 4, 155-166. 